\title{
Etnisite Farklılığının Ağrı Duyarlılığına ve Hemşirelik Bakım Sürecine Etkisi*
}

\author{
The Effect of Ethnicity Differences on Pain Sensitivity and Nursing Care Process
}

Meryem Türkan Işıki, Tuğba Çam Yanıkii

\author{
'Dr.Öğr.Üyesi, Mersin Üniversitesi, Hemşirelik Fakültesi, Hemşirelik Esasları AD, https://orcid.org/0000-0002-4091-8583
}

iiAraş. Gör., Mersin Üniversitesi, Hemşirelik Fakültesi, Cerrahi Hastalıkları Hemşireliği AD, https://orcid.org/0000-0002-9053-9397

Öz

Amaç: Bu derleme, literatürde etnisite farklılı̆̆ıın ağı duyarlılığına etkisine yönelik yapılan çalışmaları incelemek ve hemşirelik bakımındaki önemini tartışmak amacıyla yapıldı.

Gereç ve Yöntem: Çalışmanın evrenini "Cochrane", "Pubmed", "Wiley Online Library" veri tabanları ile "Google Scholar" taranarak ulaşılan 35 makale oluşturdu. İncelemede "etnisite", "kültür", "kültürel farkııık", "ağrı duyarlılı̆ı" anahtar kelimeleri kullanılarak ağrı duyarlıı̆ı̆ının ölçüldüğü, yayın dilinin Türkçe veya İngilizce olduğu, 2009-2019 yılları arasında yayınlanan ve tam metnine ulaşılabilen makaleler derleme için seçildi.

Bulgular: Tanımlayıcı ve deneysel olarak yapılan çalışmalarda, ağrı duyarlıı̆̆ının değerlendirilmesinde ağrı duyarlılık ölçeği, mekanik-termal-duyusal testlerin kullanıldığı belirlendi. Yapılan çalışmalar sonucunda ağıı duyarlılığının, etnik köken ve kültüre göre değişebileceği ifade edilebilir. Bireylerin ağı duyarlılı̆ı ve ifade etmesi kültür yapısına göre değişiklik gösterebildiği için buna yönelik geleneksel yöntem uygulamaları da gerçekleştirilebilmektedir.

Sonuç: Günümüzde sağlık bakım profesyoneli olan hemşireler, birçok farklı etnik kökene ve kültürel farklılığa sahip hastalara bakım vermektedir. Bundan dolayı hemşire, etnisite ve kültüre göre ağrının algılanışının farklılık gösterebildiğinin farkında olmalıdır. Sağlık kuruluşlarının bu konu üzerinde gerekli önemi göstermeleri ve eğitimlerini buna göre düzenlemeleri gerekmektedir. Özellikle primer tedavi ve bakım verme rolünü üstlenen hemşireler için kültürel bakım ve ağıı duyarlılığı arasında ilişkinin kavranması ve bakıma yansıtılması yaklaşımının oldukça önemli olduğu ortadadır. Hemşireler bakım verirken etnik köken ve kültürel özelliklere göre hastaların ağrı duyarlılı̆ını belirleyerek girişimleri uygulamalıdır.

Anahtar kelimeler: Ağrı; Duyarlıık; Kültür; Etnisite; Hemşirelik Bakımı.

\section{ABSTRACT}

Objective: This review was made to examine the studies in the literature on the effects of ethnicity and cultural differences on pain sensitivity and to discuss their importance in nursing care.

Material and Method: The universe of the study was composed of 35 articles accessed by browsing "Cochrane", "Pubmed", "Wiley Online Library" databases and "Google Scholar". In the review, articles using the keywords "ethnicity", "culture", "cultural difference", "sensivity of pain" were measured for the perception of pain, the publication language was Turkish or English, and the full text of 2009-2019 was selected for the review. A total of 10 articles were discussed in the study.

Results: In descriptive and experimental studies, it was stated that pain sensitivity scale, mechanical-thermal-sensory tests were used to evaluate pain sensitivity. As a result of the evaluation of these studies, it can be stated that pain sensitivity may change according to the culture. As a result of the studies, it can be stated that pain sensitivity may change according to the culture. Since individuals' sensitivity and expression of pain can vary depending on the culture structure, traditional methods can be applied for this.

Conclusion: Nurses who are health care professionals nowadays, it provides care to patients of many different ethnic and cultural differences. Accordingly, the nurse should be aware of the perception that pain may differ according to ethnicity and culture. Health institutions should show the necessary importance on this issue and organize their education accordingly. It is obvious especially for nurses who have a primary treatment and care role that understanding the relationship between cultural care and pain sensitivity and reflecting on care. Nurses should apply the interventions by determining the pain sensitivity of the patients according to ethnicity and cultural characteristics while providing care.

Keywords: Pain; Sensitivity; Culture; Ethnicity; Nursing Care.

*Lokman Hekim Dergisi, 2020; 10 (3): 302-308

DOI: $10.31020 /$ mutftd. 742348

e-ISSN: 1309-8004, ISSN 1309-761X

Geliş Tarihi - Received: 25 Mayıs 2020; Kabul Tarihi - Accepted: 21 Ağustos 2020

iletişim - Correspondence Author: Tuğba Çam Yanık<tugbacam@mersin.edu.tr> 


\section{Giriş}

Latincede korumak, ikamet etmek gibi anlamları olan kültür kavramının kökeninin 'colere' kökünden türetilen 'cultura'ya dayandığı ifade edilmektedir. ${ }^{1}$ İnsanlar tarafından öğrenilen, öğretilen ve nesilden nesile aktarılan değer, inanç, tutum ve davranış paylaşımları kültür olarak adlandırılmaktadır. ${ }^{2}$ Türk Dil Kurumu'nun tanımına göre ise kültür; "Tarihsel, toplumsal gelişme süreci içinde yaratılan bütün maddi ve manevi değerler ile bunları yaratmada, sonraki nesillere iletmede kullanılan, insanın doğal ve toplumsal çevresine egemenliğinin ölçüsünü gösteren araçların bütünüdür" şeklinde belirtilmektedir. ${ }^{3}$ Genel olarak kültür, çeşitli bağlamlarda sabit olan algı, yapı, inançlardan oluşan "kalıcı bir model" olarak tanımlanabilir. ${ }^{4}$

Paylaşımların nesilden nesile aktarılmasını sağlayan kültür; insanların sağlığının korunmasında, varlık ve refahının sağlanması ve sürdürülmesinde önemli bir olgudur. Geçmişten bugüne oluşan kültürel farklılaşmaları çok kültürlü topluluklar oluşturmuştur. Sağlık ve hastalık kavramları değer yargılarına göre şekillenmiş ve kültürün etkisinde kalmıştır. ${ }^{5}$ Bu etkiler, her kültürün sağlık ve hastalık değerlerine karşı gösterdiği tutum ve davranışlarda farklııklara neden olmuştur. Farklı kültürden insanlara sağlık hizmetinin verilmesi konusunda bilgilendirmenin önemli hale gelmesi nedeniyle tüm sağılı ekibi üyelerinin, farkı kültürden insanlara sağlık bakım hizmetini sunabilmeleri için, gerekli bilgi ve beceriler kazandırılarak eğitilmeleri gerekmektedir. ${ }^{6}$

Sağlık alanında, kültürden kültüre algılayış ve yaşayış biçiminde farklııık gösteren durumlardan birisi ağrıdır. Latince 'poena' sözcüğüyle bağlantılı olan ağrı, hoş olmayan bir uyaran sonucunda duygusal ve algısal süreçlerin yaşandığı bir durum olarak ifade edilmektedir. ${ }^{7,8}$ Uluslararası Ağrı Araştırma Derneği'ne göre ise ağrı, doku yaralanması sonucunda gerçekleşen ve hoşnut olunmayan bir duyu ya da duygusal deneyim olarak tanımlanmaktadır. ${ }^{9}$ Insanlık tarihi kadar eski bir deneyim olan ağrıyı aile, duygusal boyutlar, cinsiyet, yaş gibi faktörler etkilemektedir. Ağrı, kültürel öğrenmeye ve birçok bireysel faktöre bağlı kişisel bir deneyim olarak da tanımlanabilir. ${ }^{7,8}$ Birey tarafından deneyimlenen ve çok boyutlu olan ağrının algılanması ve ağrıya yönelik davranışlar kültüre göre değişkenlik göstermektedir. ${ }^{4,10}$ Bireyin kültürel farklılıkları, ağrının algılanması sonucunda çeşitli tepkiler sergilenmesine neden olabilmektedir. Örneğin, birey tarafından yaşanan acı durumunun reddedilmesi veya olumlu gösterilen davranışlar kültürel farklılık nedeniyle verilen tepkilerden biridir. Bu tepkinin değişkenlik göstermesinin sebebi, bireyin geçmişinde yaptığı yanlış yaklaşımlar veya eylemlerin cezası olarak ağrıyı yaşadığını düşünmesi sonucunda bedeninde oluşan ağrıyı kabul etmemesidir. Bireyin ağrı yaşaması durumunda kendini çaresiz hissetmesi sonucunda ağlama eyleminde bulunması, yaşamakta olduğu ağrı durumunu hafifletebileceğini düşündürebilir. Latinler ağrıyı yaşamın bir parçası olarak, ağrıyı bir acı çekme, cezalandırma olarak gördüğü için sadece dua ederek ve rahip tarafından kutsanarak acıların hafifleyeceğine inanırlar. İrlandalı bireyler ise ağrıya tahammül etmeyi gurur duyulması gereken bir acı olarak algılamakta, bu süreçte yalnız kalmak istedikleri ifade edilmektedir. ${ }^{11}$

\section{Kültürel Olarak Ağrı Duyarlılığı ve Hemşirelik Bakım Süreci İçin Önemi}

Bireyler, yetiştikleri toplumun değerlerine ve kültürlerine göre nasıl hasta olunacağını ve hasta rolünü öğrenmektedirler. ${ }^{8}$ Kültüre özgü öğrenilmiş davranışlar ağrının kontrol edilmesinde oldukça etkili olabileceğinden, ağıının kültürel olarak değerlendirilmesi hemşire bakım sürecinde önemlidir. Kültürel değerlerin dikkate alınarak bakımın verilmesi hastanın bakıma katılımını sağlar. ${ }^{7,12}$ Bunun sonucunda bireyin ağrıya duyarlııı̆ı da değişmektedir. Kültür, ağrı duyarlıı̆̆ı, ağrının yoğun veya hafif hissedilmesi yani bireyde oluşacak ağrı eşiğinde ve tolerans düzeyinde önemli etkiye sahip olabilmektedir. Çoğu etnik tutumlarda yüksek ağrı toleransı takdir edilirken aynı zamanda ağrıyı erkeklerin kadınlara göre daha çok tolere etmeleri beklenebilmektedir. ${ }^{8}$ Ağrıya verilen tepki, kültürel alt yapının etkisinde olup hemşire bakım süreci için ağrının değerlendirilmesinde önemlidir. Hastanın ağrı ifadeleri (yüz buruşturma, inleme, ovma vb.) hemşire tarafından bilinmeli ve bu ifadelere karşı anlayışlı olunmalıdır. ${ }^{8,13,14}$ Örneğin doğum ağrısını yaşayan ve dini 
inançları güçlü olan bir kadın, bu ağrıyı hayatının önemli bir parçası olarak gördüğü için kabullenmekte ve daha rahat kontrol edebilmektedir. Bazı hastalar, ağrıyı özel bir durum olarak kabul ettiği için ağrı algısını dışa vurmayabilir. Bireyin sahip olduğu kültürel değerler doğrultusunda ağrı tepkileri; bağırma, ağlama, tepkisiz kalma şeklinde farklılıklar gösterebilir. ${ }^{12}$ Hemşire, ağrıyı deneyimleyen bireye kültürel açıdan yapılması gerekenler öncellikle hastanın ağrı hakkında ne düşündüğü ve ağrı ile ilgili korkuları sorulmalı, sonrasında ağrıya yönelik tutumlarını belirlenmeli, bireye göre ağrı algısı tanımlamalıdır. Hastanın ağrıya yönelik kültürel girişimleri bitki, çay ve halk hekimi ilaç kullanma durumu sorgulanmalı, ağrı yönetimi konusunda hastanın fikirlerini ifade etmesi cesaretlendirilerek ve hastayla birlikte hemşirelik girişimleri planlanmalıdır. Hemşire ağrıyı değerlendirmede, hastaya uygun ağrı değerlendirme ölçekleri kullanılmalı, hastanın ağrıya yönelik uyguladığı dini ve kültürel davranışlara duyarlı olmalıdır. Ağrı sürecinde hastanın gereksinimine yönelik uygulanan hemşirelik girişimleri, bakım kalitesini arttırarak hasta memnuniyetini de yükseltir. ${ }^{7,12}$

\section{Gereç ve Yöntem}

Bu literatür taramasının amacı, etnik değişikliklerin ve kültürel farklıı̆̆ın ağrı duyarlıı̆ı̆ına etkisini irdelemek ve hemşirelik bakımındaki önemini tartışmaktır. Literatür taraması Ocak 2020- Mayıs 2020 tarihleri arasında yapıldı. Literatürde bulunan çalışmalar 2009-2019 yılları arasında "Cochrane", "Pubmed", "Wiley Online Library" ve "Google Scholar" veri tabanları ile taranarak "etnisite", "kültür", "ağrı duyarlılı̆ı", "kültürel farklılık" anahtar kelimelerin bulunduğu makaleler oluşturdu. Elektronik arama sonucunda saptanan makaleler araştırmacılar tarafından bağımsız olarak gözden geçirildi. Çalışma kapsamına alınacak makalelerin seçiminde; (1) ağrı duyarlılı̆ının ölçüldüŭğ çalışma olması, (2) yayın dilinin Türkçe veya İngilizce olması, (3) son 10 yılda (2009-2019) yayınlanmış olması, (4) tam metnine ulaşılabilmesine dikkat edilmiştir. Araştırma türü olarak ise tanımlayıcı, deneysel çalışmalar dikkate alındı. Toplamda konu ile ilgili 35 araştırmadan 25 kaynak dahil etme kriterine uymadığı için elendi, derleme için 10 çalışmanın tam metinleri kaynak olarak alındı. Seçilen çalışmalar farklı kültürden bireylerin ağrıyı algılamasına yönelik farklılıklarını kapsamaktadır. Verilerin özetlenmesi için geliştirilen form içerisinde çalışmalar kısaca özetlendi (Tablo1). Veri özetleme formunda çalışmanın yazarları, yılı, çalışmanın yöntemi ve sonuçları yer almaktadır. Araştırmacılar arasında fikir anlaşmazlığı yaşanmadı.

\section{Bulgular}

Bu literatür taramasında 2009-2019 yılları arasında yayınlanan 10 tane çalışmaya yer verilmiştir. Derlemede incelenen çalışmalar 'kültürel olarak ağrı duyarlıı̆̆ı' başlığı altında incelenerek Tablo1'de çalışmanın yazarları, yöntemi ve sonuçları özetlendi. Yapılan çalışmalar tanımlayıcı ve deneysel olup i̇sveçli, Çinli, Kanadalı, İspanyol, Amerikalı, İngiliz, Libyalı, Kazak, Latin, Hintli bireylerin ağıı algılarını değerlendirmiştir (Tablo 1). Çalışmaya dahil edilen makalelerde bireylerin ağrı duyarlılıklarının kültürel çeşitliliklerine göre farklılıklar gösterdiğini ortaya koyduğu belirlendi. ${ }^{14,15-23}$

Dawson ve List yaptığı çalışmada, İsveçliler'in Orta Doğulu bireylere göre ağrı duyarlılı̆ının algometre testinde $(p<0,01)$ ve soğuk basınç testinde $(p<0,001)$ anlamlı olarak daha yüksek olduğunu belirtmiştir. ${ }^{15}$

Hsieh ve ark.'nın yaptığı başka çalışmada, Çinli öğrencilerin Avrupalı Kanadalı öğrencilere göre ağrıya duyarlılıklarının daha düşük olduğu $(p<0,001)$ bulunmuştur. ${ }^{16}$

Rowell ve ark.'nın çalışmasında, Asyalılar ve İspanyol olmayan beyazlardaki ağrı algısı-duyarlılığına baktıkları çalışmada ise Asyalıların, İspanyol olmayan beyazlara göre ağrı duyarlılıklarının daha yüksek olduğunu ifade ettikleri saptanmıştır $(p<0,05) .{ }^{17}$ 
Tablo 1. Kültürel olarak ağrı duyarlılığına yönelik yapılan çalışmalar

\begin{tabular}{ll}
\hline Çalışma & Yöntem \\
\hline Dawson ve List(2009)15 & Orta Doğulular ve İsveçlilerin ağrı eşiklerinin ve ağrı \\
& duyarlılıklarının karşılaştırıldığı çalışmaya, 32 Orta \\
& Doğulu ve 32 İveçli birey dahil edilmiştir. Her bir \\
& katılımcıya üç tane ağı testi uygulanan çalışmada, \\
& ağrı eşiği ve ağrı duyarlılı̆ı algometre (mekanik \\
& uyarı), elektriksel uyarı ve soğuk basınç testi (termal \\
& uyarı) uygulanmıştır. \\
\hline Hsieh ve ark.(2010)16 & Genç erişkin Çinli ve Avrupa Kanadalılarının ağrı \\
& algıları ve ağrıya cevaplarının karşılaştırıldığı \\
& çalışmada 80 Çinli ve 80 Avrupa Kanadalı öğrenciye \\
& ağrı algılarının değerlendirilebilmesi için, 'Ağrı \\
& Tutumu-Algısı Ölçeği' uygulanmıştır. Ağrının \\
& değerlendirilmesinde ise 'Mc-Gill Ağrı Ölçeği' \\
& kullanılmıştır.
\end{tabular}

Rowell ve ark.(2011)17 Asyalılar ve İspanyol olmayan beyazlardaki ağrı algısıduyarlııı̆ına bakılan çalışmaya, 30 Asyalı ve 30 İspanyol olmayan beyaz katılımcılar dahil edilmiştir. Çalışmaya katılanların ağrı duyarlııkları ortalama arteryel basınç, kalp atım hızı değerlendirilmiştir. Katılımcıların ağrı eşiği ve ağrı duyarlılıkları soğuk basınç testi ile ölçülmüştür.

Wandner ve ark.(2012) ${ }^{18} \quad$ Florida Üniversitesi'nde okuyan 111 öğrenci ile planlanan çalışma, Kazak, Afrikan Amerikalı, Asyalı, Latin, Hintli Amerikan bireylerin oluşturduğu 73 kişi ile yapılımıştır. 'Irka göre ağrı değerlendirmesi' anketi ve demografik özelliklerin bulunduğu anketlerin bireylerden elektronik yol ile doldurulmas istenmiştir.

\section{Sonuç}

Çalışmaya katılan bireylerde algometre ve soğuk basınç testi uygulandığında ağrı eşiğinde anlamlı bir fark bulunmamıştır $(p>0,05)$. Bununla birlikte çalışmada, İsveçlilerin ağrı duyarlılığının algometre testinde $(p<0,01)$ ve soğuk basınç testinde $(p<0,001)$ anlamlı olarak daha yüksek olduğu belirtilmiştir.

Çalışmanın sonucunda T-testi kullanılarak Çinli ve Avrupalı Kanadalı öğrencilerin arasında anlamlı bir fark olmadığı saptanmıştır $(p>0,05)$. Ayrıca Çinli ve Avrupa Kanadalıların ağrı eşiği arasında anlamlı bir fark olmadığı $(p>0,05)$ fakat Çinli öğrencilerin ağrıya duyarlılıklarının anlamlı olarak daha düşük olduğu $(p<0,001)$ bulunmuştur.

Asyalılarda ortalama arteryel basınç ile ağrı duyarlılığı arasında anlamlı bir fark olmadığı $(p>0,05)$, Asyalıların anlamlı olarak íspanyol olmayan beyazlara göre ağrı duyarlılığının daha yüksek olduğu ifade edilmiştir $(p<0,05)$.

Çalışmanın sonucunda Asyalı bireylerin siyahi bireylere göre ağrı duyarlılıklarının daha fazla olduğu $(p<0,05)$ ve beyaz bireylerin ise diğer katılımcılara göre ağrı duyarlılıklarının fazla olduğu ifade edilmiştir.

Çalışmada, büyük yetişkin bireylerin orta yaşı yetişkin bireylere göre ağrı duyarlılıklarının anlamlı olarak daha fazla olduğu saptanmıştır $(p<0,001)$. Ayrıca büyük yetişkin bireylerin genç yetişkin bireylere göre ağrı duyarlııklarının da fazla olduğu bildirilmiştir. Çalışmanın sonucunda Libyalı öğrencilerin ağrı duyarlılıklarının İngiliz öğrencilere göre daha yüksek olduğu saptanmıştır $(p<0,05)$. arasında ağıı duyarlılığının incelendiği çalışmada, katılımcıların ağrıya duyarlılıkları submaksimal efor turnike testi ile değerlendirilmiştir.

Chan $(2013)^{20} \quad$ Avrupalı $(n=24)$ ve Asya Amerikalı $(n=33$, Asya Amerikalıların arasından 12 kişi Çin, Tayvan, Kore ve Vietnamlı birinci kuşak göçmenler ve 21 kişi ise Birleşmiş Milletlerde doğan ikinci kuşak) öğrencinin katıldığı çalışmada fiziksel ağrı duyarlıı̆̆ı, soğuk basınç testi uygulanan hastaların öncelikle bir eli bileğine kadar oda sıcaklı̆̆ı ile dolu olan bir kaba batırılarak değerlendirilmiş̧ir. Sonraki aşamada ise aynı el soğuk suya batırılmış ve dayanabildiği kadar dayanması istenmiştir. Buna yönelik olarak bireylerin ağıı eğişi ve ağrı duyarlıııkları karşılaştırılmıştır.

Bisogni ve ark.(2014) ${ }^{21}$ İnvaziv girişim uygulanan ittalyan ve Çinli çocuk hastaların ağrıyı algılayışları arasındaki farklılıkları üzerinde yapılmış kesitsel bir çalışmadır. Çalışmaya 314 yaş arasında olan, 92 Çinli ve 239 italyan çocuk hasta dahil edilmiştir. Çalışmada invaziv girişim uygulanan çocukların 3-7 yaş arasında olan grubun ağrı değerlendirmesi 0-10 Wong yüz skalası ve 7 yaş üzerindeki çocuklarda ise $0-10$ arası sayısal ağrı değerlendirmesi ölçeği kullanılmıştır.

Al-Harthy ve ark. (2016) ${ }^{14}$ Temporomandibular bozukluk rahatsızlığı olan 39 Suudi Arabistanlı, 42 İtalyan ve 41 İsveçli kadın hasta ile çalışma yapılmıştır. Çalışmada hastalara mekanik ve elektriksel olarak ağrı verilmiş ve hastaların ağrıyı
Çalışma sonucunda; birinci kuşak
Amerikalılarda ikinci kuşağa göre ağrı eşiği
anlamlı olarak anlamlı olarak
bulunmuştur $(p<0,05)$

Çalışmada, birinci kuşak Asya Amerikalılarda ikinci kuşağa göre ağrı duyarlıığı da anlamlı olarak daha düşük bulunmuştur $(p<0,05)$. İkinci kuşak Asya Amerikalılar ile Avrupa Amerikalılar arasında ise anlamlı bir fark bulunmamıştır $(p>0,05)$.

Çalışmanın sonucunda; minimal invaziv işlemlerde Çinli çocukların ortalama ağrı puanı İtalyan çocuklara göre anlamlı olarak daha yüksek bulunmuştur $(p<0,05)$.

Çalışmada, İsveç ve Suudi Arabistanlı bireylerin ağrıyı algılamada aralarında anlamlı fark olmadığı $(p>0,05)$, İtalyan bireylerin ağrıyı daha az algıladıklarını ifade ettikleri 


\begin{tabular}{|c|c|c|}
\hline & $\begin{array}{l}\text { algılamaları ölçülmüştür. } \\
\text { değerlendirilmesinde Kademeli Kronik ağrı ölç̧ıği } \\
\text { kullanılmış ve çalışmaya katılanların ağrılarını 0-10 } \\
\text { arasında değerlendirmeleri istenmiştir. Ayrıca } \\
\text { elektriksel stimülasyon testlerinin ölçülmesinde de } \\
\text { sabit akım elektriksel uyarımlı bir mikroişlemci olan } \\
\text { PainMatcher ile değerlendirilmiştir. }\end{array}$ & $\begin{array}{l}\text { saptanmıştır. Ayrıca, Italyan kadınların } \\
\text { mekanik ve elektriksel uyarılara İsveçli } \\
\text { kadınlara göre duyarlılıklarının yüksek } \\
\text { duyarlılığı olduğu belirtilmiştir. }\end{array}$ \\
\hline Bell ve ark.(2018) ${ }^{22}$ & $\begin{array}{l}\text { Afrikan Amerikalılar ( } n=57) \text { ve İspanyol olmayan } \\
\text { beyazlar }(n=57) \text { ile etnik farklııkların ağıı } \\
\text { duyarlılığına etkisine bakılan prospektif çalışmada } \\
\text { ağrı duyarlılığı, Ağrı Duyarlılık Ölçeği ile } \\
\text { değerlendirilmiştir. }\end{array}$ & 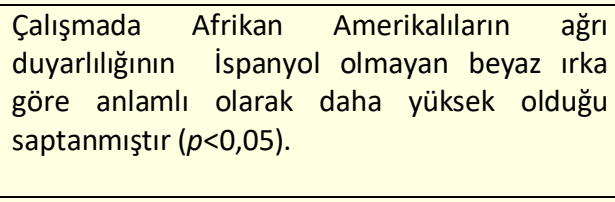 \\
\hline Kim ve ark.(2019) ${ }^{23}$ & $\begin{array}{l}\text { İspanyol olmayan beyaz ( } n=1637) \text {, Afrikan Amerikalı } \\
\text { ( } n=1012) \text {, Asyalı }(n=299) \text { ve İspanyol }(n=211) \text { olmak } \\
\text { üzere toplamda } 3159 \text { sağlıklı bireyin alındığı kesitsel } \\
\text { çalışmada, ağrı duyarlılığının değerlendirilmesinde } \\
\text { Ağrıyı Felaketleştirme Ölçeği (Pain Catastrophizing } \\
\text { Scale) kullanılmıştır. Çalışmada bireylerin basınç } \\
\text { ağrısı, mekanik deri ağrısı ve ısı ağrısına yönelik ağıı } \\
\text { duyarlılıkları test edilmiştir. }\end{array}$ & $\begin{array}{l}\text { Çalışmada, Afrikan Amerikalıların ve } \\
\text { Asyalıların İspanyol olmayan beyazlara göre } \\
\text { ısıya karşı ağrı duyarlııklarının daha yüksek } \\
\text { olduğu ifade edilmiştir. }\end{array}$ \\
\hline
\end{tabular}

Wandner ve ark.'nın çalışmasında, 111 üniversite öğrencisi ile yaptıkları çalışmada, Asyalı öğrencilerin, siyahi öğrencilere göre ağrı duyarlııklarının daha fazla olduğunu $(p<0,05)$ ve beyaz öğrencilerin diğer öğrencilere göre ağrı duyarlılıklarının daha fazla olduğunu ifade etmiştir. ${ }^{18}$

Alabas ve ark.'nın çalışmasında, Libyalı öğrencilerin ağrı duyarlılıklarının İngiliz öğrencilere göre daha yüksek olduğunu saptamıştır $(p<0,05){ }^{19}$

Chan ve ark.'nın, Avrupalı ( $n=24)$ ve Asya Amerikalı ( $n=33$, Asya Amerikalıların arasından 12 kişi Çin, Tayvan, Kore ve Vietnamlı birinci kuşak göçmenler ve 21 kişi ise Birleşmiş Milletlerde doğan ikinci kuşak) öğrencinin katılımıyla yaptığı çalışmada; birinci kuşak Asya Amerikalılar'da ikinci kuşağa göre ağrı eşiği anlamlı olarak daha düşük bulunmuştur $(p<0,05)$. İkinci kuşak Asya Amerikalılar ile Avrupa Amerikalıların ağrı duyarlııklarının arasında ise anlamlı bir fark bulunmamıştır $(p>0,05) .{ }^{20}$

Bisogni ve ark.'nın yapmış olduğu çalışmada, ise minimal invaziv işlemlerde Çinli çocukların, İtalyan çocuklara göre ağıı puanlarının daha yüksek olduğu saptamıştır $(p<0,05) .{ }^{21}$

Al-Harthy ve ark.'nın, Suudi Arabistan, İtalyan ve İsveçli bireylerin kültürünün ağrıyı algılamaları üzerine etkisini araştırdıkları çalışmada, İsveç ve Suudi Arabistanlı bireylerin ağrıyı algılamada aralarında anlamlı fark olmadığı ( $p>0,05)$, İtalyan bireylerin ağrıyı daha az algıladıklarını ifade ettikleri saptanmıştır. ${ }^{14}$

Bell ve ark.'nın, Afrikan Amerikalılar ( $n=57$ ) ve İspanyol olmayan beyazlar ( $n=57$ ) ile etnik farklııkların ağrı duyarlıı̆̆ına etkisini araştırdığı prospektif çalışmada, Afrikan Amerikalılar’ın ağıı duyarlılığının diğer ırka göre daha yüksek olduğu saptanmıştır $(p<0,05) .{ }^{22}$

Kim ve ark.'nın, kesitsel olarak, İspanyol olmayan beyaz ( $n=1.637)$, Afrikan Amerikalı ( $n=1.012)$, Asyalı $(n=299)$ ve ispanyol $(n=211)$ olmak üzere toplamda 3.159 sağlıklı bireyle yaptıkları çalışma sonucunda Afrikan Amerikalıların ve Asyalıların İspanyol olmayan beyazlara göre ısıya karşı ağrı duyarıııkları daha yüksek bulunmuştur. ${ }^{23}$

\section{Tartışma}

Bireyin/hastanın etnik köken farklıı̆̆ı, kültürel farklıııkları, ağrı tecrübesi ağrı duyarlılığını değişebilmektedir. Yapılan çalışmalar özellikle ağrı duyarlılı̆ının kültürler arasında algılanış farklıı̆ı̆ndan etkilendiğini ortaya koymaktadır. ${ }^{14-23}$ 
Yapılan çalışmalarda İsveçlilerin Orta Doğululara göre ağrı duyarlılığının daha fazla olduğu, Çinli öğrencilerin Avrupa Kanadalı öğrencilere göre ağıı duyarlılığının düşük olduğu, Asyalıların İspanyol olmayan beyazlara göre ağrı duyarııı̆ının daha yüksek olduğu, Asyalı bireylerin siyahi bireylere göre ağrı duyarlılıklarının daha fazla olduğu, Libyalı öğrencilerin ağrı duyarlılıklarının İngiliz öğrencilere göre daha yüksek olduğu, Çinli çocukların ortalama ağrı puanının (ağrı duyarlılı̆ı) İtalyan çocuklara göre daha yüksek olduğu, İtalyan bireylerin İsveçli ve Suudi Arabistanlı bireylere göre ağrı duyarlııklarının daha düşük olduğu, birinci kuşak Asya Amerikalılar'da ikinci kuşağa göre ağrı eşiği anlamlı olarak daha düşük Afrikan Amerikalıların ve Asyalıların ağrı duyarlılığının İspanyol olmayan beyaz ırka göre anlamlı olarak daha yüksek olduğu gösterilmektedir. ${ }^{14-23}$ Çin kültürüne göre duyguların gösterilmesi engellenmektedir. Fakat yapılan çalışmalarda ise Çinli bireylerin ağrı duyarlılığın yüksek veya düşük olduğu görülmektedir. Çin kültürünün bireylerin ağrı duyarlılı̆ını arttıran veya azaltan etkisinin olduğunu söylemek mümkün olmayabilir. ${ }^{16}$ Bireylerin kültürel farklıııklarına göre ağrı duyarlııkları farklılık gösterse de, aynı kültüre sahip bireylerin davranışlarında farklılıkların olduğu da gözlenmektedir. Toplumda bireyler aynı kültürel çevrede yaşa da, o kültürü benimseyip hayatında uygulamaya geçirmesinde farklılıklar olduğu sonucu çıkartılabilir.

Sağlık bakım sürecinde hasta için ağrının anlamının öğrenilmesi önemlidir. Bireyin/hastanın ağrısını azaltmada hangi yöntemleri kullandığı, kullandığı bu yöntemlerin ağrıya olan etkisinin takibini yapan hemşire için önemlidir. Hemşire tarafından sağlık bakım hizmetinin sunulduğu hastanın ağrıya yüklediği anlamın ortaya çıkarılması önemlidir. Ağrının yönetiminde hemşire, hastanın kültürel inanç ve iyileşme uygulamalarını içeren bir planlama yapılmalıdır. Hemşire hasta tarafından yaşanılan ağrının kültürel etkilerinin farkında olmalı, ağrı değerlendirmesi ve ağrıya yönelik uygulamalar kültüre uygun bir şekilde yapılmalıdır. ${ }^{7}$

Globalleşmenin gerçekleşmesiyle birlikte hemşirelerin sağlık bakım sürecinde hastayı kültürel açıdan yetkin bir biçimde değerlendirerek yaklaşım sergilemesi oldukça önemlidir. Özelliklede sağlık bakım sürecinde ağrının değerlendirmesine yardım edeceği için, hemşirelerin ağrıyı kültürel açıdan anlaması, değerlendirmesi ve sağılı sunum yaklaşımını bu doğrultuda gerçekleştirmesi gerekmektedir. Hemşire tarafından hastanın ağrıyı anlaması, ağrıya verilen tepkisi değerlendirilirken, etnik köken ve kültürel değerler dikkate alınmalıdır. Ağrıyı değerlendirme sürecinde hemşire ile hasta arasında kültürel farklııklardan dolayı iletişim kurmada bazı sorularda yaşanabilmektedir. iletişim ile ilgili sıkıntıların yaşanmasının azaltılması için hemşire hasta ile yavaşça konuşmalı, basit ve açık görüşlü olmalıdır. Eğer iletişim sırasında tercüman kullanılıyorsa tercümanın kültürel olarak duyarlı olması gerekmekte ve hasta ile hemşire arasındaki iletişimin kolaylaştırmayı sağlamalıdır. ${ }^{11,24}$

\section{Sonuç ve Öneri}

Birey/hastanın etnisite farklııkları ve kültürel özelliklerine göre ağrıyı yaşama davranışları değişebilmektedir. Genel olarak kültürel farklılıklar arasında en sık ağrıya verilen en değerli tepkinin sessiz ortamda ağrının yaşanması olarak açıklandığı söylenebilir. Farklı etnik köken ve kültürler arasında hasta tarafından ağrıyı ifade etmek yerine kontrol etmenin daha iyi olduğu düşünülmektedir. Günümüzde sağlık bakım profesyoneli olan hemşireler, birçok farklı etnik kökene ve kültürel farklılığa sahip hastalara bakım vermektedir. Hemşire, bakım sunduğu hastanın etnik kökeni ve kültüründen kaynaklı ağrı duyarlııklarının farklıık gösterebildiğinin farkında olmalı ve buna yönelik bakım sürecini planlamalıdır. Böylece hastanın ağrıya yönelik uygulamaların sağlığına zarar veya yarar sağladığının farkına vararak daha kaliteli ve hasta odaklı bakımın sunulmasını sağlayabilir.

\section{Bilgi}

Çıkar çatışması yoktur. 


\section{KAYNAKLAR}

1. Doğan Ö. Kültür Bilimleri ve Kültür Felsefesi. 6. baskı. İstanbul: Notos Kitap; 2012: 1-8.

2. Taşçı S. Sağlık ve hastalığı etkileyen kültürel faktörler. İçinde: Seviğ Ü, Tanrıverdi G, Editörler. Kültürlerarası Hemşirelik. 1.baskı. İstanbul: Akademi Yayıncılık; 2014:19-30.

3.Türk Dil Kurumu (TDK) Genel Türkçe Sözlük. http://www.tdk.gov.tr/index.php?option=com_gts\&kelime=KÜLTÜR. (Erişim: 03.02.2020)

4. Gooberman-Hill R. Ethnographies of pain: Culture, context and complexity. British Journal of Pain 2015; 9(1): 32-35.

5. Erci B. Halk Sağlığı Hemşireliği (2.Baskı). Amasya: Göktuğ Yayıncılık. http://www.goktugyayin.com.tr/kitap_detay.asp?id=56. 2014 yılında basıldı. (Erişim: 02.02.2020)

6. Koçak Y, Terzi E. Türkiye'de göç olgusu, göç edenlerin kentlere olan etkileri ve çözüm önerileri. Kafkas Üniversitesi İktisadi ve İdari Bilimler Fakültesi Dergisi 2012;3(3):163-184.

7. Köksal Ö, Duran ET. Doğum ağrısına kültürel yaklaşım. Dokuz Eylül Üniversitesi Hemşirelik Fakültesi Elektronik Dergisi 2013;6(3):1-6.

8. Eti Aslan F. Tarihsel süreçte ağrı. 2. Baskı. İçinde: Eti Aslan F, editör. Ağrı Doğası ve Kontrolü. Ankara: Akademisyen Tıp Kitapevi; 2014: 3-8.

9. The International Association for the Study of Pain (IASP). https://www.iasp pain.org /Education/Content.aspx?ItemNumber=1698\#Pain. (Erişim: 15.04.2020)

10. Pillay T, vanZyl HA, Blackbeard D. Chronic pain perception and cultural experience. Procedia-Socialand behavioral sciences 2014;113:151-160.

11. Jin M. Pain assessment tools used when caring through cultural boundaries: a qualitative systematic literature review [Degree Thesis]. Health Care and Social Welfare. 2017; Vaasa.

12. Kuğuoğlu, S. Ağrı algısını etkileyen faktörler. 2. Baskı. İçinde: Eti Aslan F, editör. Ağrı Doğası ve Kontrolü. Ankara: Akademisyen Tıp Kitapevi; 2014:51-55.

13. Goyal MK, et al. Racial disparities in painmanagement of children with appendicitis in emergency departments. JAMA Pediatrics 2015;169(11):996-1002.

14. Al-Harthy M, et al. List T. The effect of culture on pain sensitivity. Journal of Oral Rehabilitation 2016;43(2):81-88.

15. Dawson A, List T. Comparison of pain thresholds and pain tolerance levels between Middle Easterners and Swedes and between genders. Journal of Oral Rehabilitation 2009;36(4):271-278.

16. Hsieh AY, et al. Comparisons of catastrophizing, pain attitudes, and cold-pressor pain experience between Chinese and European Canadian young adults. The Journal of Pain 2010;11(11):1187-1194.

17. Rowelll LN, et al. Asians differ from non-Hispanic Whites in experimental pain sensitivity. European Journal of Pain 2011; 15(7): 764-771.

18. Wandner LD, et al. The perception of pain in others: how gender, race, and age influence pain expectations. The Journal of Pain 2012; 13(3): 220-227.

19. Alabas OA, Tashani OA, Johnson MI. Effects of ethnicity and gender role expectations of pain on experimental pain: $A$ cross-cultural study. European Journal of Pain 2013; 17(5): 776-786.

20. Chan MY, Hamamura T, Janschewitz K. Ethnic differences in physical pain sensitivity: Role of acculturation. PAIN ${ }^{\circledR}$ 2013;154(1):119-123.

21. Bisogni S, et al. Cross-sectionalstudy on differences in pain perception and behavioral distress during venipuncture between Italian and Chinese children. Pediatricreports 2014;6(3):1-9.

22.Bell BA, et al. Ethnic differences identified by pain sensitivity questionnaire correlate with clinical pain responses. Regional Anesthesia \& Pain Medicine 2018;43(2):200-204.

23.Kim HJ, et al. Racial/ethnic differences in experimental pain sensitivity and associated factors-Cardiovascular responsiveness and psychological status. PloS one 2019;14(4):1-22.

24. Türkiye Cumhuriyeti Hasta Hakları Yönetmeliği, Resmî Gazete Tarihi: 01.08.1998. Resmî Gazete Sayısı: 23420 (Erişim: 17.08.2020) 